\title{
Enterprise Modeling According to Enterprise Architects
}

\author{
Małgorzata Pańkowska \\ Department of Informatics, University of Economics, Katowice, Poland \\ Email:pank@ue.katowice.pl
}

How to cite this paper: Pańkowska, M. (2021). Enterprise Modeling According to Enterprise Architects. Open Journal of Social Sciences, 9, 636-647.

https://doi.org/10.4236/jss.2021.99047

Received: July 29, 2021

Accepted: September 26, 2021

Published: September 29, 2021

\begin{abstract}
In the context of enterprise modeling, this paper is to explain business modeling. The enterprise modeling has been developed to support different stakeholders in their decision-making processes. Managers, auditors, enterprise architects, and business developers have particular expectations concerning the enterprise and they need conceptual modeling. Beyond that, business units, i.e., customers, producers, cooperators, and suppliers are interested in the conceptual modeling and enterprise models. In this paper, author argues that conceptual modeling is necessary for enterprise management, and particularly for internal auditing. Author uses the enterprise architecture approach, presents enterprise architecture frameworks; discusses enterprise modeling methods, languages, and tools to reveal the opportunity to apply conceptual modeling for enterprise management. This paper aims to present the application of Assurance Map, tasks and goal modeling in an integrated conceptual model.
\end{abstract}

\section{Keywords}

Enterprise Modeling, Enterprise Management, Assurance Map, iStar, Goal Modeling Language, ArchiMate

\section{Introduction}

Enterprise Architecture (EA) ensures comprehensive understanding and evaluation of the current and desired state of any business organization. It reveals opportunities for integration of Information Communication Technology (ICT) resources and prevents the development of inconsistent business processes and low quality information. The ISO/IEC/IEEE 42020:2019 defines architecture as concepts and properties of an entity, which can be an enterprise, understood as an organization addressing particular challenges and issues combined with 
processes. The EA serves to guide managers in designing business processes and information system developers in building software applications that are in line with business vision, mission, strategic objectives and policies. The EA ensures a holistic view of business processes, systems, information and technology of the enterprise (Hazra \& Unhelkar, 2021). The EA requires models and modeling processes to translate business vision and strategy into efficient and effective ICT components. The results of enterprise architect's work cover the desired ICT strategies, the new or modified EA, the new or modified set of EA standards, and a roadmap describing the ICT projects for EA implementation (Minoli, 2008). This paper aims to answer the research questions, i.e., RQ1: How business models and modeling issues are discussed in the enterprise modeling publications, and RQ2: How can enterprise architects implement business models without ICT designing and implementation. To answer the first RQ, the literature survey method is applied and for answering the second RQ the integrated model is proposed and discussed. The paper consists of three sections. The next section includes discussion on EA modeling approaches and enterprise modeling frameworks. The third section includes a systematic literature review results on enterprise modeling in the aspect of business model development and application. Further, the author's model integration is presented. This integrated model is a solution that combines ArchiMate language model, iStar 2.0 Goal Modeling Language (GoalML) enterprise model, and the Assurance Map for auditing tasks. This integrated model is to support the business organization operational management and internal auditing, as well as to illustrate that conceptual modeling is needed for business management.

\section{Business Issues in Enterprise Architecture Frameworks}

Within the EA scope, the business architecture determines the structure of the enterprise in terms of its governance structure, business processes, and business information. In description of the enterprise, business architecture concerns business partners, finances, and the ever-changing market to align strategic business goals with decisions regarding products and services, partners and suppliers, their capabilities and key initiatives.

In general, the enterprise architects develop the enterprise modeling as a discipline capturing relevant knowledge and providing motivation to design information systems that support the business organization management. First and foremost, they focus on architecture-driven support of the digital transformation of business units. However, for enterprise architects, capturing the business motivation to this transformation, evaluation of digital transformation process and results, and business requirements for designing are challenges. Although enterprise architects focus on the EA development for the digital transformation, the question is how they answer these challenges and what other applications of EA are possible.

Nowadays, EA is a discipline of designing enterprise guided with principles, 
frameworks, methodologies, requirement, tools, reference models and standards. There are many frameworks that support the EA modeling and development, e.g., Zachman Framework (ZF), Generic Enterprise Reference Architecture and Methodology (GERAM), Purdue Enterprise Reference Architecture (PERA), Computer Integrated Manufacturing Open System Architecture (CIMOSA), Lightweight Enterprise Architecture (LEA), Nolan Norton Framework (NNF), Extended Enterprise Architecture Framework (E2AF), Enterprise Architecture Planning (EAP), Federal Enterprise Architecture Framework (FEAF), Treasury Enterprise Architecture Framework (TEAF) (Bernus, Nemes, \& Schmidt, 2003). The mentioned frameworks are the ICT artifact-oriented and only some of them (e.g., ZF, CIMOSA, Unified Architecture Framework (UAF), the Ministry of Defense Architectural Framework (MODAF), or The Open Group Architecture Framework (TOGAF)) include business issues considerations and deeper analysis on strategic and operational management.

The Zachman Framework provides a basic structure for organizing business architecture through dimensions such as data, function, network, people, time, and motivation (Zachman, 2010). Zachman describes the ontology for the enterprise through negotiations among several actors. The ZF presents various views and aspects of the enterprise architecture in a highly structured form. It differentiates between the levels: Scope (i.e., contextual and planner view), Enterprise Model (i.e., conceptual and owner view), System Model (i.e., logical and designer view), Technology Model (i.e., physical and builder view), and Detailed Representation (i.e., out-of-context and subcontractor view), and Functioning Enterprise (i.e., user view). In the ZF model, for each view, there are six questions, i.e., What? How? Where? Who? When? and Why? Taking into account the question Why? the enterprise architect is required to analyze the enterprise business plan, strategies and rules. Hence, the business goals, processes, enterprise stakeholders, and their resources are modelled and controlled. Similarly, the business issues' considerations are included in the MODAF, which covers seven viewpoints, i.e., All View, Acquisition, Strategy, Operational, System, Service, and Technical viewpoint (Perks \& Beveridge, 2003).

The CIMOSA framework is based on four abstract views (i.e., function, information, resource and organization views) and three modeling levels (i.e., requirements definition, design specification, and implementation description (Spadoni \& Abdmouleh, 2007). The four modeling views are provided to manage the integrated enterprise model. The role of each view is to filter components out of the model according to a given perspective. For the management of views, CIMOSA architects assume a hierarchy of business units that are grouped into divisions.

The TOGAF Model (2021) comprises the Architecture Development Method (ADM) that includes references to diagram types, e.g., Application Communication Diagram, Application and User Location diagram, Enterprise Manageability Diagram, and Application Migration Diagram. The ArchiMate language is fundamental for the enterprise modeling according to TOGAF. It enables modeling 
of the business issues, applications and technology artifacts, as well as business motivation issues, which explain a context for the ICT implementation in a business unit. The Unified Architecture Framework (UAF) is the next generation architecture framework derived from the Department of Defense Architecture Framework (DODAF) and MODAF (UAF, 2020). The UAF is applied for modeling the security controls, threats, risks, and risk mitigation. It includes elements needed for defining capabilities, requirements, operational behaviors, ICT and business resources, data, and personnel.

\section{Business Issues in Enterprise Modeling Frameworks}

The term "enterprise" means a concept to identify a company, social organization or governmental institution. An enterprise is defined as a consciously coordinated social entity, with a relatively identifiable boundary and achievable goals (Hoogervorst, 2009). In enterprise engineering, system theory and system approach have dominated for the last fifty years, and the enterprise engineering is underpinned by two fundamental concepts, i.e., ontology and architecture. Both these concepts are valid for the enterprise modeling. Although the concept of "enterprise engineering" is still valid, the enterprise modeling is a subject of interest of many researchers. Figure 1 includes a comparison of publications on enterprise modeling and enterprise engineering in Scopus in 2010-2021. The numbers are similar, although enterprise engineering dominates in the computer science.

In general, enterprise modeling covers the presentation of business goals, processes, resources, data, and stakeholders. Each element can be supported as a particular viewpoint by a different modeling language and visualized separately. The resulting enterprise models are to be synchronized since they all make statements to provide a complete and holistic representation of the enterprise. There are some approaches, which are declared by their authors as developed particularly for enterprise modeling, e.g., Multi-Perspective Enterprise Modeling (MEMO), Design and Engineering Methodology for Organizations (DEMO),

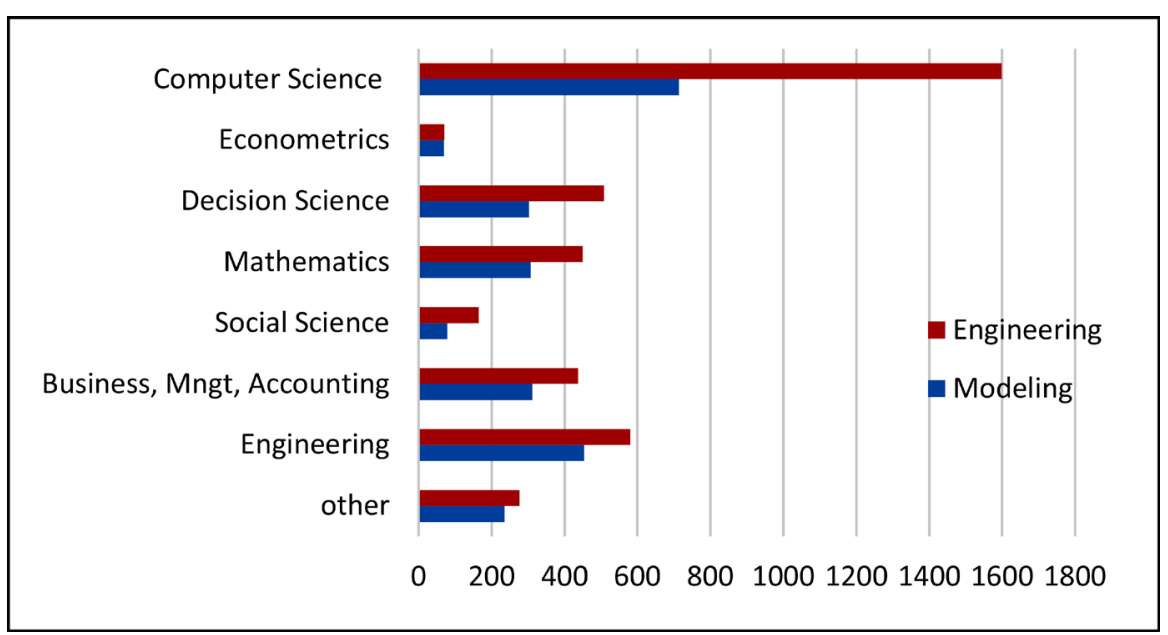

Figure 1. Publications on enterprise engineering and enterprise modeling in Scopus. 
Semantic Object Model (SOM), Enterprise Architecture Modeling (EAM), and Four Enterprise Modeling (4EM). The MEMO framework includes modeling languages for various domains such as business processes, organizational structures, corporate strategies, and object models (Bock \& Frank, 2016). In enterprise modeling, the use of Domain-Specific Modeling Language (DSML) provides researchers with concepts that are reconstructed from the relevant domain of discourse. It enables modeling productivity as they do not need to construct domain-specific concepts from basic linguistic constructs. The MEMO framework included three main languages to model the organizational action system. Hence, the Goal Modeling Language (GoalML) enables the design and analysis of enterprise goal system. The iStar software is the GoalML tool (Dalpiaz, Franch, \& Horkoff, 2016). The second is the Organization Modeling Language (MEMO OrgML), which allows to model organizational structures and business processes. The last one is the Information Technology infrastructure Modeling Language (ITML). The MEMO framework comprises four key elements, i.e., a high level framework, domain-specific modeling languages, and accompanying methods and tools. The high-level conceptual framework represents a holistic perspective on an enterprise that includes three other sub-perspectives, i.e., strategy, organization, and information system. They are further detailed into various aspects, i.e., resources, structure, process, and goal. Perspectives are supplemented and characterized by problem classes and they are associated with corresponding modeling methods. Although Frank (2014) argues that MEMO business models provide an important abstraction to improve organizational performance and competitiveness, he elaborates the models for software system development.

According to the DEMO framework developers, an enterprise consists of three coherent and mutually dependent organizational layers, i.e., the B-organization (business), the I-organization (information), and the D-organization (document) and modeling should concern all three layers (Dietz, 2006). Beyond that, DEMO framework includes four other models, i.e., the Cooperation Model, the Action Model, the Process Model and the Fact Model (Dietz, 2021). These models are also interrelated. The Cooperation Model is a model of cooperation between the organization's actors. The Action Model covers the organization's operations, action rules, and work instructions. The Process Model covers the organization's landscape of processes and links among them. The Fact Model is a model of the products in the organization and it contains the specification of entity types, value types, property types and attribute types, which all are appropriate for the modeled enterprise. The Semantic Object Model is a comprehensive methodology for modeling business systems. A business system is defined as an open, goal-oriented, and socio-technical system, which interacts with its environment. The SOM methodology focuses on the tasks and resources of the business system, analysis of chances and risks, as well as on additional analysis of the strengths and weaknesses of the enterprise. Strategies of products, markets, 
business resources, processes, and business rules are objects of considerations (Ferstl, Sinz, \& Bork, 2016). The 4EM methodology developers propose to focus on a modeling procedure, performance of enterprise modeling in the form of a project with predetermined goals, rules and roles, involvement of the enterprise stakeholders and the domain experts in this project, and choose appropriate modeling tools. This approach concentrates on business modeling, however technical components and requirement models are also included for further information system development (Sandkuhl, Stirna, Persson, \& Wisotzki, 2014).

The ISO 19439:2006 on enterprise modeling framework proposes to consider the following four views: function and process view, information and object view, resource and infrastructure view, and organization view. Hence, the enterprise functionalities and human behaviors, information objects and relationships among them, human and technical components, and their capabilities and competencies, as well as organizational units, decision centers and decision levels are to be included in an enterprise model. The ISO 19440:2020 proposes to analyze the following views of an enterprise: function, information, organization, resource, collaboration, and decision. The organization view includes the organizational and decisional structure of the enterprise, the responsibilities and authorities, and decision centers in the enterprise. Resource view comprises people and things in a specific context. Collaboration view is developed to reveal the material, informational, and financial flows and exchanges among the enterprise's internal units and between the enterprise and its value chain partners. Decision view enables to represent decision-making processes, decision system structure, topics, their categories, criteria, and dependencies. To summarize, enterprise modeling is to provide abstract representations, i.e., artifacts to support understanding, analysis, design, reasoning, administration, monitoring, control, and even learning on the enterprise. In fact, the EM is the art of presenting the knowledge in the form of models about the structure, functionalities, management, and maintenance of the whole or a part of an enterprise, as well as the relationships with its environment. The goal is to model the enterprise to increase the efficiency, profitability, effectiveness, competitiveness, and sustainability of the enterprise. The conceptual model is always an abstraction, simplified representation, and approximation of the reality, which is observed by developer or researcher.

The answer to the RQ1 How business models and modeling are discussed in the enterprise modeling publications, is included in the systematic literature review results. The literature search was done using the following databases: Association of Information Systems electronic Library (AIS eLib), Emerald Insight, Scopus, Sage Journals, and IEEEXplore. Search term was a combination of "enterprise" AND "modeling" AND "management". The search yielded a total of 2496 papers published in 2010-2021. However, based on titles, keywords, and abstracts only 36 papers were deemed to be of potential interest. Finally, just 9 the most meaningful papers have been included in Table 1 . The searching string 
Table 1. Enterprise Modeling (EM) in Literature Survey.

\begin{tabular}{|c|c|}
\hline Reference & Research Findings \\
\hline $\begin{array}{l}\text { Fayoumi \& Williams, } \\
2021\end{array}$ & $\begin{array}{l}\text { The paper considers EM from a socio-technical systems (STS) perspective } \\
\text { and a new model of enterprise was derived from STS theory and combined } \\
\text { with STS practices. }\end{array}$ \\
\hline Vernadat, 2020 & $\begin{array}{l}\text { The paper summarizes the research works on enterprise modeling in the } \\
\text { last four decades, outlining the modeling constructs, tools, and methods. }\end{array}$ \\
\hline Bider \& Lodhi, 2019 & $\begin{array}{l}\text { The paper evaluates whether EM helps in an analysis of hypotheses for } \\
\text { radical change of Business Model Innovation. That analysis supports new } \\
\text { assets acquisition }\end{array}$ \\
\hline $\begin{array}{l}\text { Vallespir \& Ducq, } \\
2018\end{array}$ & $\begin{array}{l}\text { The paper presents the evolution of the EM techniques from the divergence } \\
\text { era to the convergence time, to model-driven approaches and } \\
\text { interoperability problem solving. }\end{array}$ \\
\hline $\begin{array}{l}\text { Stirna \& Sandkuhl, } \\
2018\end{array}$ & $\begin{array}{l}\text { Authors argue that enterprise model consists of a number of related } \\
\text { sub-models, each describing the organization from a particular view, i.e., } \\
\text { process, rule, goal, actor, or data. However, in each case, the individual set } \\
\text { of models can be created. }\end{array}$ \\
\hline Alpers et al., 2018 & $\begin{array}{l}\text { Authors focus on modeling privacy from business and software engineering } \\
\text { perspective. }\end{array}$ \\
\hline $\begin{array}{l}\text { Petrikina, Drews, } \\
\text { Schirmer, \& } \\
\text { Zimmermann, } 2014\end{array}$ & $\begin{array}{l}\text { Authors analyze the possibilities for integrating the enterprise architecture } \\
\text { and business model. }\end{array}$ \\
\hline $\begin{array}{l}\text { Arachchige, Weigand, } \\
\text { \& Jeusfeld, } 2012\end{array}$ & $\begin{array}{l}\text { In this paper, a meta-modeling approach is used to map the service } \\
\text { modeling language with value network ( } \mathrm{e} 3 \text { value), data and process model. }\end{array}$ \\
\hline $\begin{array}{l}\text { De La Fuente, Ros, \& } \\
\text { Ortiz, } 2010\end{array}$ & $\begin{array}{l}\text { The paper proposes an enterprise modeling methodology to support the } \\
\text { supply chain reengineering and integration. }\end{array}$ \\
\hline
\end{tabular}

“enterprise” AND “modeling” AND “management” provided so many results, because there are plenty of possible interpretations of these three words as well as many combinations of these concepts. The differentiation of research methods and techniques is high. There are papers focusing strictly on enterprise modeling in ArchiMate or Unified Modeling Language (UML), but there are also papers on econometric modeling of the enterprise and use of statistical methods. Shen (2021) introduced the modeling and analysis of the complex system of human capital accumulation in high-tech enterprises based on big data. $\mathrm{He}$ proposed an application of regression analysis and the analytic hierarchy process (AHP).

\section{Enterprise Management Integrated Model}

The intriguing nature of management subject and a variety of goals, which enterprises pursue, raises the need for enterprise modeling towards specific managerial demands in organizations. In order to address these requirements an integrated model is proposed. This approach takes into account that enterprise architects do not reject the idea of a model's integration.

The proposed model refers to the combination of enterprise modeling methods for particular business purposes and applied in particular business situa- 
tions. The business operational management results from long-term strategic management and includes short-term planning, decision making, organization of human, physical, and financial resources, realization of processes, controlling and auditing of business effectiveness, efficiency, resilience, value creation, security, and privacy protection. The strategic management covers the formulation of the business strategy, its realization, evaluation, and improvement. Fundamental processes of management and auditing are included in Figure 2.

In this paper, the integrated model combines the Business Model written in the ArchiMate language (Figure 2), Business Goal Model visualized in iStar tool for GoalML (Figure 3), and the Assurance Map developed for auditing tasks monitoring (Figure 4). All the models are combined through actors, goals, and tasks. Assurance Map and assurance-based management are the objective examination tools to perform an independent assessment over business activities (Practice Guide, 2021). The primary purpose of the Assurance Map is to detect areas of gaps and duplications in assurance efforts among business units. There are four assurance levels representing the quality and the level of evidence by each department (Figure 4). The High Assurance ( $\mathrm{H}$ on Green) is detailed and cyclically conducted. As it is critical for business actors, controls are provided, risks are mitigated, and policies are communicated. The Medium Assurance ( $M$ on Yellow) is not cyclically performed, but occasionally realized. Some risks are neglected, policies are not fully elaborated, and the controls are not automated. The Low Assurance ( $\mathrm{L}$ on Orange) means lack of significant concerns over the adequacy of control. The None Assurance ( $\mathrm{N}$ on Red) means lack of assurance and lack of policies. Empty cells mean indetermination or non-applicability. The Assurance Map is created individually for each enterprise to enable understanding the

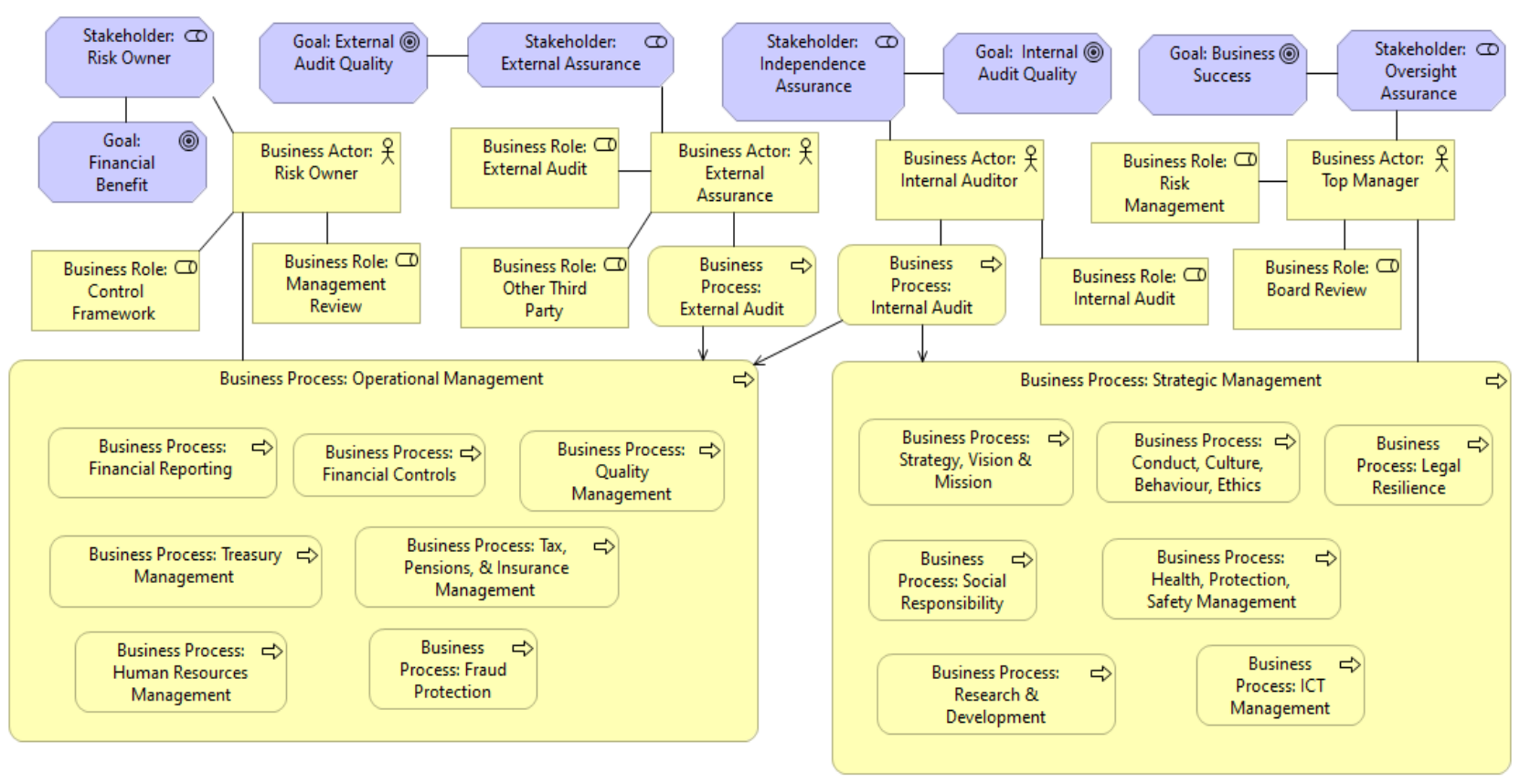

Figure 2. Processes, Stakeholders, Business Actors, Goals and Roles in ArchiMate model. 


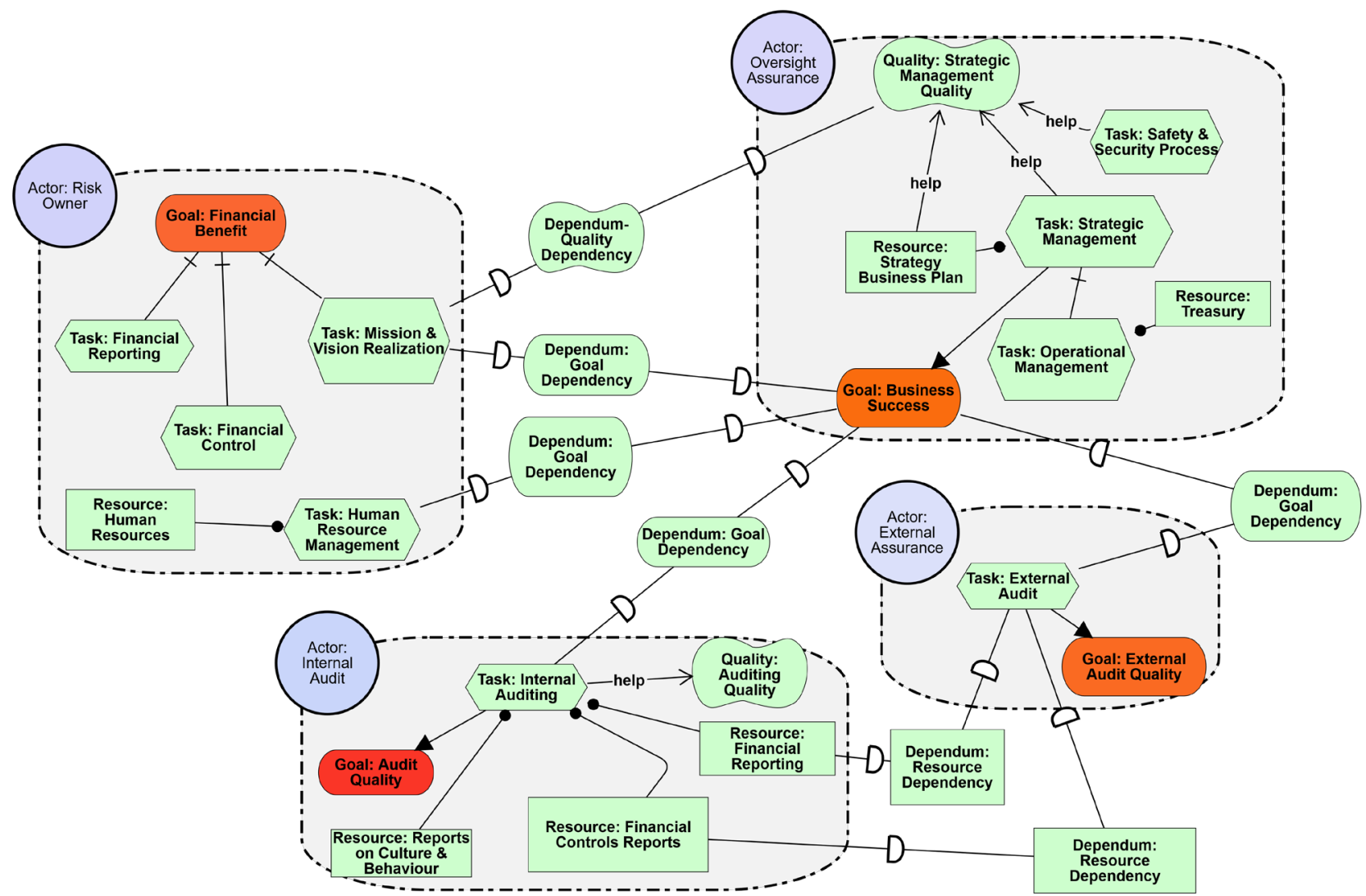

Figure 3. Actors, goals, tasks and resources, and their interdependencies in GoalML model.

\begin{tabular}{|c|c|c|c|c|c|c|c|c|}
\hline \multirow[b]{2}{*}{ Assurance Activity } & \multirow[b]{2}{*}{$\begin{array}{c}\text { Risk } \\
\text { evaluation }\end{array}$} & \multicolumn{2}{|c|}{$\begin{array}{c}\text { Management first line -Risk } \\
\text { Owners }\end{array}$} & \multicolumn{2}{|c|}{$\begin{array}{l}\text { Functions second line - } \\
\text { Oversight Assurance }\end{array}$} & \multirow{2}{*}{ 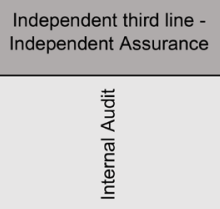 } & \multicolumn{2}{|c|}{$\begin{array}{l}\text { External fourth line - } \\
\text { External Assurance }\end{array}$} \\
\hline & & 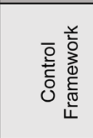 & 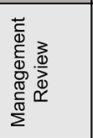 & 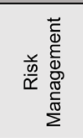 & 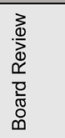 & & 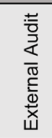 & 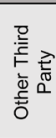 \\
\hline Strategy, Vision \& Mission & $\mathrm{L}$ & $N$ & $\mathrm{H}$ & $M$ & $\mathrm{H}$ & $M$ & $\mathrm{~L}$ & \\
\hline Conduct, Culture, Behaviour, Ethics & $\mathrm{L}$ & $\mathrm{L}$ & M & M & M & $\mathrm{H}$ & $\mathrm{N}$ & M \\
\hline Financial Controls & $\mathrm{H}$ & $\mathrm{H}$ & $\mathrm{H}$ & $\mathrm{M}$ & $M$ & $\mathrm{H}$ & $\mathrm{H}$ & \\
\hline Business Legal Resilience & $\mathrm{L}$ & $\mathrm{L}$ & $L$ & $\mathrm{M}$ & $\mathrm{M}$ & $\mathrm{L}$ & $\mathrm{M}$ & L \\
\hline Information Communication Technology (ICT) & $\mathrm{M}$ & $\mathrm{L}$ & $L$ & $\mathrm{M}$ & $\mathrm{H}$ & $\mathrm{L}$ & $\mathrm{L}$ & \\
\hline Treasury & $\mathrm{H}$ & $\mathrm{M}$ & $\mathrm{M}$ & $\mathrm{H}$ & $\mathrm{M}$ & $\mathrm{N}$ & $\mathrm{L}$ & \\
\hline Tax, Pensions \& Insurance & $\mathrm{L}$ & $\mathrm{M}$ & $M$ & $\mathrm{~L}$ & $\mathrm{~L}$ & $\mathrm{~N}$ & $\mathrm{~L}$ & \\
\hline Human Resources & $\mathrm{M}$ & $\mathrm{M}$ & $\mathrm{H}$ & $\mathrm{L}$ & $\mathrm{M}$ & L & & \\
\hline Fraud & $M$ & $M$ & L & $\mathrm{L}$ & $\mathrm{L}$ & $\mathrm{M}$ & $\mathrm{L}$ & \\
\hline Health, Privacy Protection \& Safety & $M$ & $M$ & $M$ & $\mathrm{H}$ & $\mathrm{H}$ & $\mathrm{L}$ & & $\mathrm{H}$ \\
\hline Quality Management & $\mathrm{M}$ & $\mathrm{M}$ & $\mathrm{H}$ & $\mathrm{M}$ & $\mathrm{L}$ & $\mathrm{L}$ & & \\
\hline Research \& Development & $M$ & $\mathrm{~L}$ & $M$ & $\mathrm{H}$ & $\mathrm{M}$ & $\mathrm{L}$ & & \\
\hline Social Responsibility, Corporate Image & $\mathrm{L}$ & $\mathrm{N}$ & $\mathrm{L}$ & $\mathrm{L}$ & $\mathrm{H}$ & $\mathrm{M}$ & $\mathrm{N}$ & \\
\hline
\end{tabular}

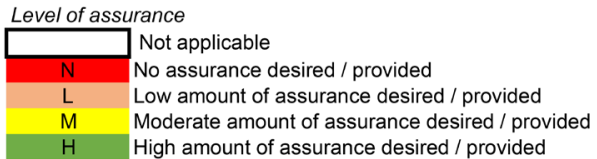

Figure 4. Activities, actors, risks and assurance level in assurance Map model.

key risks and to support compliance and business resilience.

\section{Conclusion}

Although there are many approaches to enterprise modeling, conceptual mod- 
eling can be useful not only to the design and implementation of ICT, but the artifacts created are valuable for business management, in particular for controlling and planning business activities and responsibilities. Dealing with the artifacts requires the managers to understand their developed models in relation to those who focus on the artifacts' implementation in practice, e.g., controllers, supervisors.

\section{Conflicts of Interest}

The author declares no conflicts of interest regarding the publication of this paper.

\section{References}

Alpers, S., Pilipchuk, R., Oberweis, A., \& Reussner, R. (2018). Identifying Needs for a Holistic Modelling Approach to Privacy Aspects in Enterprise Software Systems. ICISSP2018-Proceedings of the $4^{\text {th }}$ International Conference of Information Systems Security and Privacy (pp. 74-82). https://doi.org/10.5220/0006606200740082

Arachchige, J. J., Weigand, H., \& Jeusfeld, M. (2012). Business Service Modeling for the Service-Oriented Enterprise. International Journal of Information System Modeling and Design, 3, 1-22. https://doi.org/10.4018/ijismd.2012010101

Bernus, P., Nemes, L., \& Schmidt, G. (2003). Handbook on Enterprise Architecture. Springer. https://doi.org/10.1007/978-3-540-24744-9

Bider, I., \& Lodhi, A. (2019). Using Enterprise Modeling in Development of New Business Models. ICEIS 2019-Proceedings of the $21^{\text {st }}$ International Conference on Enterprise Information Systems, 2, 525-533. https://doi.org/10.5220/0007769205250533

Bock, A., \& Frank, U. (2016). Multi-Perspective Enterprise Modeling-Conceptual Foundation and Implementation with ADOxx. In D. Karagiannis, H. C. Mayr, \& J. Mylopoulos (Eds.), Domain-Specific Conceptual Modeling, Concepts, Methods and Tools (pp. 269-290). Springer. https://doi.org/10.1007/978-3-319-39417-6_11

Dalpiaz, F., Franch, X., \& Horkoff, J. (2016). iStar 2.0 Language Guide. https://arxiv.org/pdf/1605.07767.pdf

De La Fuente, M. V., Ros, J., \& Ortiz, A. (2010). Enterprise Modelling Methodology for Forward and Reverse Supply Chain Flows Integration. Computers in Industry, 61, 702-710. https://doi.org/10.1016/j.compind.2010.05.010

Dietz, J. L. G. (2006). Enterprise Ontology, Theory and Methodology. Springer. https://doi.org/10.1007/3-540-33149-2

Dietz, J. L. G. (2021). The DEMO Specification Language v 4.6. https://ee-institute.org/download/demo-specification-language-4-6/

Fayoumi, A., \& Williams, R. (2021). An Integrated Socio-Technical Enterprise Modelling: A Scenario of Healthcare System Analysis and Design. Journal of Industrial Information Integration, 23, Article ID: 100221. https://doi.org/10.1016/j.jii.2021.100221

Ferstl, O. K., Sinz, E. J., \& Bork, S. D. (2016). Tool Support for the Semantic Object Model. In D. Karagiannis, H. C. Mayr, \& J. Mylopoulos (Eds.), Domain-Specific Conceptual Modeling, Concepts, Methods and Tools (pp. 291-312). Springer.

https://doi.org/10.1007/978-3-319-39417-6_13

Frank, U. (2014). Multi-Perspective Enterprise Modeling: Foundational Concepts, Prospects and Future Research Challenges. Software and System Modeling, 13, 941-962. https://doi.org/10.1007/s10270-012-0273-9 
Hazra, T. K., \& Unhelkar, H. (2021). Enterprise Architecture for Digital Business, Integrated Transformation Strategies. CRC Press. https://doi.org/10.1201/9781315120409

Hoogervorst, J. A. P. (2009). Enterprise Governance and Enterprise Engineering. Springer. https://doi.org/10.1007/978-3-540-92671-9

ISO 19439:2006. Enterprise Integration-Framework for Enterprise Modelling. Geneva: International Standard Organization. https://www.iso.org/standard/33833.html

ISO 19440:2020. Enterprise Modelling and Architecture-Constructs for Enterprise Modelling. Geneva: International Standard Organization. https://www.iso.org/standard/74491.html

ISO/IEC/IEEE 42020:2019. Software, Systems and Enterprise-Architecture Processes. Geneva: International Standard Organization. https://www.iso.org/standard/68982.html

Minoli, D. (2008). Enterprise Architecture A to Z, Frameworks, Business Process Modeling, SOA, and Infrastructure Technology. CRC Press. https://doi.org/10.1201/9781420013702

Perks, C., \& Beveridge, T. (2003). Guide to Enterprise IT Architecture. Springer. https://doi.org/10.1007/b98880

Petrikina, J., Drews, P., Schirmer, I., \& Zimmermann, K. (2014). Integrating Business Models and Enterprise Architecture. 2014 IEEE $18^{\text {th }}$ International Enterprise Distributed Object Computing Conference Workshops and Demonstrations (pp. 47-56). https://doi.org/10.1109/EDOCW.2014.16

Practice Guide: Coordination and Reliance: Developing an Assurance Map (2021). The Institute of Internal Auditor, North America.

https://na.theiia.org/standards-guidance/recommended-guidance/practice-guides/Page $\underline{\text { s/coordination-and-reliance-developing-an-assurance-map.aspx }}$

Sandkuhl, K., Stirna, J., Persson, A., \& Wizotzki, M. (2014). Enterprise Modeling, Tackling Business Challenges with the 4EM Method. Springer. https://doi.org/10.1007/978-3-662-43725-4_5

Shen, Y. (2021). Modeling and Research on Human Capital Accumulation Complex System of High-Tech Enterprises Based on Big Data. Complexity, 2021, Article ID: 6635228. https://doi.org/10.1155/2021/6635228

Spadoni, M., \& Abdmouleh, A. (2007). Information Systems Architecture for Business Process Modelling. In P. Saha (Ed.), Handbook of Enterprise Systems Architecture in Practice (pp. 366-380). Hershey, PA: Information Science Reference, IGI Global. https://doi.org/10.4018/978-1-59904-189-6.ch022

Stirna, J., \& Sandkuhl, K. (2018). Enterprise Modelling: Establishing the Fundament for Capability Management. In K. Sandkuhl, \& J. Stirna (Eds.), Capability Management in Digital Enterprises (pp. 85-100). Springer.

https://doi.org/10.1007/978-3-319-90424-5_5

The TOGAF ${ }^{\circledast}$ Standard, Version 9.2. (2021). The Open Group. https://publications.opengroup.org/downloadable/customer/products/

UAF OMG Unified Architecture Framework. Unified Architecture Profile (UAFP) Version 1.1 (2020). Object Management Group. https://www.omg.org/spec/UAF/1.1/UAFP/PDF

Vallespir, B., \& Ducq, Y. (2018). Enterprise Modelling: From Early Languages to Models Transformation. International Journal of Production Research, 56, 2878-2896. https://doi.org/10.1080/00207543.2017.1418985

VERNADAT, F. (2020). Enterprise Modelling: Research Review and Outlook. Computers 
in Industry, 122, Article ID: 103265. https://doi.org/10.1016/j.compind.2020.103265

Zachman, J. A. (2010). Framework Standards: What's It All About? In L. A. Kappelman (Ed.), The SIM Guide to Enterprise Architecture (pp. 66-70). CRC Press. 